Trapaga, I. (2018). La Comunidad, una revisión al concepto antropológico. Revista de Antropología y Sociología: VIRAJES, 20(2), 161-182. DOI: 10.17151/rasv.2018.20.2.9.

\title{
La comunidad, una revisión al concepto antropológico
}

IBAN TRAPAGA*

Recibido: abril de 15 de 2018

Aprobado: junio 4 de 2018

Artículo de Investigación

* Doctor en Ciencias Antropológicas. Universidad Autónoma de Ciudad Juárez (UACJ), Ciudad Juárez, México. E- mail: iban.trapaga@uacj.mx. @ ORCID: 0000-0002-1113-8908. Google Scholar 


\title{
Resumen
}

La comunidad como concepto socio-antropológico surgió a la par de la Ciencia Social. En este artículo estableceré un recorrido histórico del término para reflexionar sobre los alcances contemporáneos del mismo en la investigación y pedagogía socio-antropológicas. La revisión bibliográfica es necesariamente sintética. El criterio de selección de esta ha sido tomar a varios autores clásicos, los más representativos de cada paradigma socio-científico: evolucionismo, sociología comprensiva, estructural-funcionalismo y marxismo. Finalmente, una mención al transnacionalismo y otras visiones actuales. El resultado es un compendio pedagógico que por su poder analítico permite considerar al concepto tratado como ambivalente en tanto método pero como herramienta política en tanto implica un modelo social utópico.

Palabras clave: comunidad, metodología, investigación social, teoría social.

\section{Community, a review of the anthropological concept}

\begin{abstract}
The Community, as socio-anthropological concept, emerged along with Social Science. A historical tour of this concept is established in this paper to reflect on its contemporary scope in the socio- anthropological pedagogy and research. The bibliographic review is necessarily simplified. The criterion to select it has been the selection of several classic authors, the most representative of each socio-scientific paradigm: evolutionism, comprehensive Sociology, structural functionalism, Marxist theory. Finally, a mention of transnationalism and other current perspectives is presented. The result is a pedagogical compendium that, due to its analytical power, allows considering the concept dealt with as an ambivalent concept as a method and as a political tool insofar as it implies a utopian social model.
\end{abstract}

Key words: ccommunity, methodology, social research, social theory. 


\section{Introducción}

T a Comunidad de la Antropología es un método derivado epistemológicamente de la dicotomía conceptual comunidadsociedad, y esta, a su vez, producto del método histórico. No obstante, la sucesiva reinterpretación por el estructuralismo positivista en las Ciencias Sociales, y en la Antropología estructuralista en particular, la comunidad devino en una herramienta metodológica para estudios sincrónicos de pequeños grupos sociales, reducido a pequeños espacios locales y con el principal objetivo de extraer la esencia de su "cultura". En su mayor parte, el espíritu subyacente a estas investigaciones emanaba del resabio evolucionista -monolineal-y la alarma que despertó el acelerado etnocidio y genocidio producto de la expansión euro-capitalista hasta los confines mundiales.

En realidad, las sucesivas revoluciones industriales centradas en el Atlántico norte habían revolucionado los patrones sociales, culturales y morales de modo que la atención sociológica se concentró en la reflexión del cambio socio- cultural. Es así, como los padres fundadores -Durkheim, Weber o el mismo Tönnies-fabricaron todo un aparato epistemológico para interpretar, científicamente, la uniformemente acelerada transformación interna. El contexto, pues, nos ayuda a comprender las teorías. La oposición planteada entre comunidad y sociedad, o entre solidaridad mecánicasimple y orgánica-compleja, o entre poder carismático y burocrático, obedecen al paradigma evolucionista. Las diversas clasificaciones binarias arriba relacionadas plantean la coexistencia de dos modelos sociales, dotando de historicidad y autenticidad fundamentada en esta naturalización legitimada por lo antiguo, lo sólido que se desvanece, por el volkgeist, a formaciones socio-culturales primitivas o campesinas en extinción u homogeneización cultural; pero cuya coexistencia es conflictiva y se traduce en relaciones de dominación continuamente negociadas o reconstruidas. De aquí a la conceptualización de culturas primitivas, indígenas y populares hay escasos pasos del conocimiento. Son dos modelos de saberes (pensamiento primitivo, mágico-religioso y científico).

La comunidad, para la Antropología, ha sido más un método comparativo que un simple concepto teórico (Redfield, 1973). Realmente fungió como un medio para obtener descripciones de culturas particulares, abiertas al análisis y comparación. El método se cosificó o reificó y conformó su propia tautología conceptual, y esta a su vez produjo un concepto, un tipo de resultados y un fenómeno social en sí mismo. Precisamente, esta es la primera de una serie de dicotomías tautológicas que, desarrolladas en tres periodos consecutivos, constituye la genealogía del término. 
Planteo, pues, tres estadios de formación, a saber: evolucionista, estructural-funcionalista y estructural-marxista. E integrando este orden lineal, cuatro oposiciones epistemológicas constituyentes y constitutivas de la tradición de comunidad en Antropología: gemeinschaft vs. gesellschaft, gemeinschaft vs. community, el concepto y el método, $\mathrm{y}$, finalmente, primitiva vs. campesina. A este correlato habrá que sumar el corolario mítico-político de la comunidad cálida vs. comunidad realmente existente (Bauman, 2006).

En las próximas páginas desglosaré estas cuatro oposiciones generadoras de los principales productos del consenso socio-antropológico sobre el concepto en torno al cual gira el presente ensayo.

\section{Gemeinschaft y Gesellschaft}

Dentro del paradigma generado por la ruptura darwiniana en las Ciencias Naturales, el evolucionismo social considera el cambio sociohistórico como una superposición civilizatoria. Morgan o Engels sancionan en su obra la existencia de diferentes etapas en la línea del Progreso. Hay que considerar, pues, las propuestas conceptuales de Tönnies como insertas en este paradigma general. Este sociólogo alemán elabora una teoría del cambio social apoyándose en una construcción historicista de la noción gemeinschaft, o comunidad, enfrentado a la gesellschaft, o sociedad. El acontecimiento en sí es un proceso de cambio socio-estructural. También Marx (1974) y Engels (2003) habían considerado formaciones sociales fosilizadas derivadas de modelos históricos tecno-económicos precedentes y que, irremisiblemente, se convertían en lastres del devenir histórico y el Progreso, proyectos nacionales inviables, así como en adalides de valores conservadores, es decir, tradicionales ${ }^{1}$. Para Tönnies, en cambio, las comunidades son constituidas por valores positivos y por una ideología particular, un will o voluntad desiderativa. No olvidemos que en la tradición sociológica alemana (Tönnies o Weber) se dota al sujeto social con autonomía relativa y creadora ante el todo social. La sociedad, en la contraparte, es caracterizada como el producto de la modernización y del capitalismo. Quizá una oposición inadvertida por sucesivas revisiones y críticas a este planteamiento radique en la propuesta que yo llamaría ideológico-cultural: cada uno de los modelos operativiza un tipo de "voluntad", una abstracción que se refiere a las motivaciones colectivas. Mientras que la gemeinschaft se caracteriza por

\footnotetext{
${ }^{1}$ Posteriormente, marxistas culturales motivados, quizá, por Jameson y su neogramscianismo retomaron el estudio de las formaciones "anquilosadas", campesinas y rururbanas mayormente, como formas culturales de resistencia: las culturas populares.
} 
una voluntad "natural" , la gesellschaft es instrumentada por una voluntad "racional". Esta se interpreta como una ideología utilitarista, donde lo común que unifica al grupo descansa sobre objetivos o fines concretos y parciales que no redundan necesariamente sobre la reproducción y cohesividad del mismo, solo lo convierten en un instrumento. Así, los sentimientos unitarios desaparecen tan pronto como las metas terminan. A esta forma ideológico-asociativa le corresponderán tipos sociales, como el hombre de negocios, las autoridades políticas o los científicos. En cambio, la voluntad propia de la gemeinschaft toma al grupo como un objetivo en sí mismo, y está más definida entre el bajo estrato social, que a su vez es "condicionado" o dominado por los tipos pertenecientes a la ideología de la gesellschaft. Resumiendo esta interesante dicotomía, la Sociedad se opone a las comunidades, dominando y explotando estas formas precedentes de organización social. La ideología de la primera se orienta a la consecución y reproducción ilimitada de recursos, principalmente materiales. El complejo ideológico-discursivo de la Comunidad, en cambio, se orienta a ordenar simbólicamente la consecución y reproducción de los seres humanos en sociedad. También Tönnies, en última instancia, subraya la calidad abstractiva y no constrictiva de la dicotomía gemeinschaft - gesellschaft.

Emplazados en la longeva oposición Natura-Cultura, la Comunidad está caracterizada por elementos propios del primer nodo: emocional, orientado a los afectos, instintivo. Su contraparte, la Sociedad, asienta formas elaboradas de pensamiento, racionalizando el uso (o abuso) de sus componentes para maximizar sus recursos, y con un mentalidad orientada a la consecución de riquezas que son extraídas gracias a esta manipulación de lo que de "naturaleza" tienen los seres humanos. Y Tönnies determina lo propiamente "natural" por las relaciones primarias del parentesco u otras, pero siempre caracterizadas por lo que llamaré el principio de contigüidad, un derivado de la analogía como aptitud cognitiva humana. Más tarde, Bauman reflexionará sobre este carácter "natural" de lo comunitario proponiendo la forzada irreflexividad interna como requisito de existencia de las "comunidades de entendimiento común" (Bauman, 2006, p. 17).

\footnotetext{
${ }^{2}$ He aquí una de las principales críticas al modelo de Tönnies: su dependencia respecto a la filosofía política y moral de su tiempo (Delgado, 2005, pp. 39-40). Así se dota al pasado y al rusticismo de una sanción legitimadora apoyada por la ideología naturalista. En este sentido todas las construcciones posteriores reposan sobre este artefacto discursivo derivado de un conjunto ideológico propio de ciertos grupos políticos. No obstante, el propio Tönnies aparentemente ignoraba esta desviación ideológica de su fundamentación, ya que "hinted that the process of change from Gemeinschaft to Gesellschaft might be reversed by real causes if such existed, but not by speeches and sentimental romanticizing about the past" (Tönnies, 2002, prefacio).
} 
La contigüidad es un instrumento cognoscitivo básico entre los humanos. De ella derivan formas de comprensión, aprendizaje y, sobre todas, abstracción: la analogía. Como herramientas lingüísticas asociadas a esta última destacan la metonimia y la sinécdoque. Todas ellas se han subrayado en las últimas décadas como los fundamentos del pensamiento científico, así se trate de la rama más empirista del mismo. Pues bien, para Tönnies su gemeinschaft está conformada por las relaciones originadas en una contigüidad espacio-temporal relativamente restringida e intensa. Son relaciones cara a cara, restringidas a espacios cercanos a la experiencia (localidad) y frecuentes en el tiempo biográfico (cotidianidad). En primera instancia se corresponde con la contigüidad denominada socialmente familiar y "basada en el parentesco y la consanguinidad" (Tönnies, 1963, p. 42). En un segundo estadio, e imbricadas con el anterior, se reproducen lo que Tönnies llama comunidades "de localidad o los tipos de vecindario" (Tönnies, 1963, p. 43); y, por último, las "comunidades psicológicas", tipologizadas como relaciones "de amistad". La vecindad se fundamenta en la localidad, proporcionada por esa "familiaridad" arriba expuesta, y ordena otro tipo de actividades colectivas. En cambio, las relaciones denominadas "de amistad" caen bajo la égida de la "comunidad psicológica", son "menos instintivas y orgánicas"3, menos condicionadas por la localidad, orientadas por actividades ocupacionales e intelectivas, y en tránsito hacia las relaciones fundamentadas en el contrato social (Tönnies, 1963). Estas son las tres relaciones básicas, tipologizadas bajo el principio de contigüidad, de la comunidad tonniesiana.

Es relevante el señalar las relaciones llamadas por Tönnies "psicológicas"4 y que yo denominaría como "comunidades imaginadas" en sintonía con la ulterior propuesta de Anderson en el análisis de los nacionalismos (Anderson,1993); más adelante la retomaré. Por ahora, bastará revisar brevemente los principales componentes de la "comunidad psicológica" de Tönnies: forma suprema y auténtica de comunidad humana, elementos de vinculación religiosos (lugares sagrados, deidades adoradas...), autónoma respecto a la localidad habita en las conciencias y persiste "en los viajes a países extranjeros" (Tonnies, 1963, p. 43), esto es, mantiene la cohesión interna y la pertenencia sin dependencia plena del terruño.

\footnotetext{
${ }^{3}$ Aquí debo puntualizar que en Tönnies la organicidad hace referencia a la calidad viviente, no autómata, de las relaciones de grupo, completamente inverso al sentido otorgado por Durkheim a su tipología solidaria.

${ }^{4}$ Exactamente son referidas como "Gemeinschaft of Mind" y son expresiones de la "comunidad de la vida mental» en oposición a la vida física de la comunidad basada en la localidad.
} 
Una última revisión necesaria para esta genealogía conceptual estriba en la faceta política de la gemeinschaft, a la que me dedicaré in extenso en las conclusiones de este artículo. Baste decir para cerrar esta primera oposición, que la gemeinschaft no fue concebida como libre de conflictos internos (Tönnies consideró inadmisible para la continuidad de tal formación social la extrema y permanente estratificación social desigual). Respecto a los conflictos externos solo fue considerada como una formación con funciones defensivas ante los embates de la gesellschaft, aunque sí sugirió las relaciones dominicales gesellschaft-gemeinschaft, sobre las que Aguirre (1991) profundizó oportunamente para el caso mexicano.

\section{Gemeinschaft y Community}

Sin embargo, este diálogo académico catalizará una redefinición operada desde planteamientos epistemológicos enfrentados al original -el positivismo sociológico de tendencia comtiana- y que derivará en la revisión durkhemiana que aquí nominalizo como community por su ascendente dentro de la tradición antropológica anglófona. Tal y como señalan reseñas actuales.

El concepto científico-social de Comunidad proviene en buena medida de la mezcla de ambos conceptos - gemeinschaft y comunidad-, y la fuente de las diferentes nociones actuales del término suele ser resultado de su correspondiente combinación en grados y proporciones diferentes (Roca, 2004). Así, la Comunidad "ha constituido un objeto de estudio clásico (...) que ha generado un modo particular de estudiarla" (Roca, 2004, p. 214).

Aunque ya Maine, Tylor y, en general, la antropología evolucionista y especulativa decimonónica en algunos casos ya habían sentado los principios de la oposición arriba descrita, fue a partir del legado sociológico de Émile Durkheim cuando se introducen los matices y correcciones al incipiente concepto y método de la "Comunidad".

Otras propuestas conceptuales han abrevado de las fuentes de la gemeinschaft. Cooley, Becker o Redfield, por citar unos pocos, se han servido de esta misma dicotomía para fundamentar el cambio socio-estructural, con diferencias de acento en los componentes que formulan las oposiciones. Así, Cooley hablará de "grupos primarios", Durkheim aportará a la sociología las solidaridades dicotómicas "mecánica" y "orgánica", Becker partirá de "sociedades sagradas y seculares", Redfield de "sociedades folk y urbanas", o Maine que estableció anteriormente la oposición entre "estatus y contrato" como método analítico.

La forma mecánica de solidaridad existe en sociedades indivisas, esto es, sin una división del trabajo sistémica y sistemática (Durkheim, 1982). En 
oposición, la forma orgánica es inherente a las sociedades modernas cuya organización social del trabajo deriva en individuos y órganos conectados entre sí, perfectamente ordenados (estructurados) y mutuamente "solidarios" en tanto son funcionales entre sí y respecto al conjunto (y por ello, orgánicos). Es una alegoría tomada de las ciencias naturales, de la medicina y la anatomía. Aquí, las formas de reciprocidad están mediadas por la monetarización económica, que permite el intercambio de bienes y servicios "solidariamente" 5 .

En las antípodas, la solidaridad mecánica se ejecuta por semejanza, homogeneidad social, y sin mediaciones y sin excesiva conciencia entre los individuos e instituciones sociales primarias, como la familia, la pandilla, el clan, etcétera (Durkheim, 1982).

Manuel Delgado ha confrontado ambas concepciones - gemeinschaft y community-. Para este autor, la gemeinschaft solo existe como una representación, mientras que las "sociedades mecánicas" (Delgado, 2005, p. 51) como él las denomina, son "todo lo contrario". Precisamente, su planteamiento es importante para ilustrar la vía propuesta por el positivismo, en tanto Delgado fundamenta, y hasta apologiza, en torno de la corriente "sensible" del concepto Comunidad. Asume, como condición básica, a las comunidades tonniesianas como producto filosófico, esto es, no científico, y la define como "entidad culturalmente homogénea, congruente consigo misma y articulada orgánicamente" (Delgado, 2005, p. 57). Por su importancia para la polémica, insisto en el carácter antitético de las dos concepciones de lo "orgánico" operadas desde Tönnies y Durkheim, y que fruto de una lectura deficiente pudieran conducir a serios equívocos. Durkheim genera su exposición de la metáfora corporal de la sociedad, por lo que lo orgánico se corresponde con un sistema bien articulado. En cambio, Tönnies parte probablemente de la tradición aristotélica del término: Órganon; en tal caso, lo orgánico debe entenderse como materia viva, lo natural, en oposición a lo mecánico, esto es, lo autómata sin alma o psique. En el fondo de la discusión se hallan tendencias excluyentes de pensamiento, donde la primera resta o suprime agencia al individuo frente al todopoderoso Sistema Social, y la segunda prefiere dotar al individuo de subjetividad y agencia: el alma. Hablar de alma, entre otros imponderables, solo puede derivar en acusaciones de acientificidad. En compendio, Delgado (2005) concluye que:

\footnotetext{
${ }^{5}$ A este respecto, ya he mencionado la hipótesis de Tönnies que postula la monetarización como principal elemento de disolución o transformación en el proceso Gemeinschaft-Gesellschaft.
} 
Tanto en un caso como en otro, los individuos que se perciben a sí mismos formando una unidad sienten lo mismo; pero en el caso de la comunidad tonniesiana es en el sentido de que tienen los mismos sentimientos, mientras que en el modelo inspirado por Durkheim lo que comparten son unas mismas sensaciones. En este segundo caso, lo que vincula es una vivencia que todos comparten, sin que ello presuponga que tengan que asumir una, sumándose a ese "lo mismo" de manera siempre diferente. (p. 52)

Y aún más esclarecedor que en otros textos, se reitera en esta suerte de empirismo materialista la ahistoricidad de la community: "Lo que los individuos y los segmentos tienen en común, lo que les permite en efecto ser solidarios, no son sus ideas, ni su idiosincrasia, ni su pasado, sino sus necesidades y su derecho inalienable de verlas satisfechas"'(Delgado, 2005, p. 59).

Ambas concepciones caminaron juntas en monografías e investigaciones sociales durante décadas; en todo caso, ninguna de las herramientas paradigmáticas obtuvo una clara ventaja en su competencia. Más aún, las divergencias desembocaron en planteamientos sintéticos o, cuando menos, más neutrales. Las sucesivas reflexiones con base a la etnografía y el golpeteo contra la complejidad social desmontaron las exclusiones mutuas en la teoría de la Comunidad. Así, entre otros, Redfield construyó su programa sin salirse un ápice de la tradición positivista anglosajona, aunque con evidentes débitos respecto a la formulación primigenia de Tönnies.

\section{Concepto y Método}

Robert Redfield fue un abogado y antropólogo estadunidense formado en la tradición sociológica de la ecología urbana de la Universidad de Chicago, pero con un trabajo de campo definido por las comunidades indígenas mesoamericanas (México central, Yucatán y Guatemala). Obras como Tepoztlán A Mexican Village y Chan Kom a Mayan Village son monografías fundacionales de la disciplina antropológica en Norteamérica e influyeron ampliamente en las posteriores generaciones y sus investigaciones etnográficas.

El continuum Folk-Urbano explicitado por Redfield es continuación lógica de la tradición procesual de la gemeinschaft. El cambio social fluye sin remisión hacia la modernidad. No obstante la dicotomía, Redfield enfocó su teoría en las comunidades folk, con el fin metodológico de extraer esas culturas tan diferentes de la euro-occidental, persiguiendo en última 
instancia salvar en registros unas formas de vida que irremisiblemente caminaban hacia su desaparición, fundiéndose en la modernidad de las sociedades urbanas. Dada la influencia que el esquema de Redfield tuvo en Estados Unidos y México, amerita una consideración especial en este apartado dedicado a la metodología propiamente antropológica de la Comunidad.

La Comunidad así entendida era un todo autocontenido y aislado. Fungía como el campo experimental perfecto para la corriente positivista moldeada por las ciencias naturales, ya que las culturas, como en una probeta de laboratorio serían herméticas ante influencias externas atenuadas por el aislamiento socio-geográfico. Era tanto así, que sociológicamente funcionan en armonía, todas sus partes e individuos "participan" en la consecución del equilibrio y la paz internas; mientras que culturalmente, todos sus integrantes coincidían en un único diseño de vida. Otro tanto podemos observar del aspecto tecno-económico, donde las condiciones particulares de cada segmento (individuo, familia, sección) eran cuasiidénticas y tendían a la regulación de las desigualdades. En definitiva, el concepto operado por Redfield se mantuvo durante décadas en términos descritos arriba por Delgado y otros autores. Por ejemplo, Kearney (1996) coincide en esta definición convertida en seña de identidad antropológica y etnográfica: "Universo autocontenido, social, cultural y económicamente" (Kearney, 1996, p. 1)

Esta noción sintética de Comunidad está conformada por tres categorías y quince aspectos sustantivos (Roca, 2011, pp. 215-217) que enlistados resultan en: residencia común, continuidad temporal, relaciones sociales, unidad mínima, aislamiento social y geográfico, autonomía, autosuficiencia, vida social integral, homogeneidad, consenso cultural, representaciones colectivas propias y únicas, autoidentificación, cohesión, separación del resto de la sociedad y capacidad autónoma de acción. Centrándome ahora en las categorías constitutivas -condicionamientos materiales, concepto de totalidad y concepto de homogeneidad-intentaré proveer los suficientes elementos de comprensión necesaria para contrastar con el fenómeno social que ocupa esta disertación:

Las condiciones materiales; se refiere a elementos físicos (ecológicos y económicos) necesarios para la vida. Así, nos referimos a una residencia común, continuidad temporal relativa ya que "para hablar de comunidad humana es necesario un grupo de personas asentadas en un territorio determinado de una manera permanente" (Roca, 2011, p. 217), interacciones sociales individuales y estructurales (estructura social entendida como entramado de roles sociales), y 
número reducido o pequeño de miembros, tal como explicitan de nuevo estos autores: "Los requisitos materiales elementales, por otra parte, no precisan de grandes aglomeraciones humanas para existir. No más requieren una unidad mínima que, además, es necesaria para que el etnógrafo pueda aprehender y comprender detalladamente una comunidad" (Roca, 2011, p. 217).

- La totalidad; implica la idea de un régimen social autárquico. Algo completamente imposible, pero que es asequible desde una gradación (de lo folk a lo urbano, por ejemplo).

- La homogeneidad; ya referida por Tönnies, la intensificación espaciotemporal de las relaciones sociales facilita la formación de una conciencia cultural exclusiva. Esta relativa homogeneidad favorece la autoconciencia colectiva de unidad, el surgimiento de sentimientos de comunidad, identidades comunes, autoidentificación con el grupo, etcétera..., que en última instancia emplazan a la construcción de cierto consenso (vehiculado por el lenguaje, según Tönnies ${ }^{6}$ ) no libre de conflicto interno, como se viene señalando.

Pues bien, la aplicación de estas ideas tuvo como consecuencia una abundante cantidad de estudios y obras donde se conformaron los tópicos de la Antropología. Así, tenemos los estudios de la comunidad como continente de culturas e identidades étnicas; la comunidad como medio económico (redes sociales, capital social, ocupación laboral: campesinado) o como medio de producción y consumo; la comunidad como descripción orgánica de estructuras y funciones; la comunidad como ente político; la comunidad como contenida en un espacio, dotándolo de historia y poder: el territorio; o de una combinación graduada de todos o de una parte de los tópicos según la intención de los autores fuera comprobar el marco teórico legado o la profundización en uno o varios de los tópicos aquí explicitados. Estos estudios también se configuraban por diversos métodos y técnicas auxiliares, organizados por perspectivas teóricas. Así, la comunidad podía verse como un "todo", como un sistema ecológico, como una típica biografía, como una clase de persona, como una perspectiva existencial, como una historia, como una comunidad de comunidades, etcétera (Redfield, 1973).

Sin embargo, este caro concepto derivaba de una metodología constreñida en la arriba referida voluntad de aislar fenómenos sociales de externas y perturbadoras influencias para lograr la optimidad científica de los resultados (que pretendían verificar o falsear hipótesis teóricas), o

6 "El órgano real del consenso, a través del cual este se desarrolla e incrementa, es el lenguaje" (Tönnies, 1963, pp. 48). 
bien por el requerimiento metodológico de delimitar un fenómeno cultural específico, amén del lúgubre objetivo de capturar tantos datos como se pudiera de formas sociales "en vías de extinción", precisamente por la expansión de la modernidad y el capitalismo euroatlántico. Así pues, el producto terminó por reificarse y convertir todo intento de conocimiento en una tautología; o en el peor de los casos, en una profecía autocumplida. En estos términos lo refirió el mismo Redfield (1960), revisando su propia obra:

In consequence of such a characteristic experience with isolated and self-contained little communties, the social anthropologist developed his methods and came to conceive of his universe of comparasions. From the fact of his sole responsability to report a remote and unfamiliar way of life the anthropologist became the jack of all social science trades, learning something of the economy, family life, goverment, and religion of the people he studied. From this fact too, and from the convenient smallness and consitency of the primitive community, developed the disposition to present everything about a way of life (...) The primitive isolated, the community that is a whole all by itself, now something of an abstraction derived from many experiences approximate to the abstraction, became the model of research and the typical entity for comparasions and generalizations. (...) Of course reality is not like this. Human living is not composed of mutually isolated small primitive groups, and, in so far as it was to be arranged that way when anthropology took hold of reality at that corner of it where the primitive isolate still existed. It is curious to note that just at the time when the primitive isolate as a model of study was being stablished in anthropology, Graham Wallas was writting a book that called attention to the fact that all the world was becoming one great society. (p. 8)

El método de la comunidad fue establecido para caracterizar y comparar unidades de análisis y unidades de observación; para, mediante técnicas diversas, elucidar datos que permitieran acumular conocimiento científico sobre la cuestión del Hombre y del cambio social. Esta correlación dual entre "unidades de análisis" y "unidades de observación" representa el esfuerzo antropológico para adecuar sus características intrínsecas, limitaciones y sujetos clásicos de estudio a la metodología científico-social. Mientras que en esta, principalmente en Sociología, se establecen marcos generales de explicación y muestras de población objeto de estudio, en la antropología basada en el trabajo etnográfico no existe tal muestra de la población ya que, o bien los universos, o bien los datos recogidos, son demasiado heterogéneos para establecer comparaciones que permitan la labor nomotética. Asimismo, el extremado localismo de la observación 
limita, cuando no imposibilita, la efectiva falsación de teorías explicativas; como expresa Pujades (como se citó en Roca, 2011): “Así, mientras que el marco general o unidad de análisis posibilitaría la explicación, la comunidad, como unidad local de observación, permitiría la comprensión" (p. 220). La Antropología ha procurado diversos remedios, como la metaforización o el recurso a la metonimia para analizar sus datos demasiado fragmentarios o localistas. Es decir, o ha buscado "contextos privilegiados que contienen toda la fenomenología del nivel general" o "aquello que tiene sentido en un contexto" debe tenerlo en todos. El resultado, a la fecha, ha sido yermo.

En definitiva, la Comunidad se ha constituido como el objeto de estudio clásico de la Antropología a pesar, y como consecuencia, de que es un procedimiento de investigación para el conocimiento antropológico. Pero en la comunidad de los antropólogos, paradójicamente, pareció pesar esa intensificación espacio-temporal de sus relaciones sociales para, al final, buscar una conciencia cultural única fundamentada en "lugares sagrados" y "deidades idolatradas". La revisión crítica de lo que arriba enumeraba Redfield fue abriéndose paso ante el desafío de corregir tendencias tautológicas o refundar la disciplina, todos los paradigmas previos incluidos. Y parece que optó por lo primero, a pesar de las benéficas perspectivas generadas durante esta transición que fue protagonizada por el cambio en el sujeto ontológico clásico: la Comunidad (Kearney, 1996, pp. $1-14)$.

\section{Primitiva y campesina}

De las revisiones y constataciones previamente relacionadas, la Antropología derivó hacia un cambio ontológico. En oposición al "primitivo" o al "indígena" del evolucionismo, resolvió construir un nuevo sujeto de estudio que habitara esa comunidad desierta de pueblo en estado precapitalista. El campesinado suplió durante las décadas posteriores a la caída del sistema mundial colonial al perdido "primitivo", aunque en México se continuaran los estudios sobre "comunidades indígenas" persistiendo el método y los conceptos propios del periodo clásico de la disciplina, solapados en muchos casos por esta campesinización. En muchos casos, el giro fue tan economicista que despojó de rasgos distintivos culturales a comunidades propiamente indígenas para convertirlos en meros campesinos, esto es, productores agropecuarios. Así destacan algunas obras de Palerm (1968), Medina y Quezada (1975), y Arizpe (1972; 1986), por citar solo alguna de las figuras más relevantes. 
Tomaré a Eric Wolf como modelo teórico de la comunidad campesina, entre otras razones porque fungió como pionero y fundador de los preceptos fundamentales del nuevo concepto. En realidad, los cambios introducidos no solo fueron ontológicos, sino que afectaron tanto la metodología como las nociones previamente heredadas. Además, promovió un giro notable hacia los aspectos tecno-económicos de la comunidad, considerando los efectivos lazos con la sociedad circundante o continente, amén de introducir explícitamente el método historiográfico como complemento de las técnicas tradicionales de la Antropología y procurar una metodología que proveyera explicaciones nomotéticas, superando las limitaciones del localismo etnográfico. Otro aspecto renovado fue la búsqueda de métodos que introdujeran en los estudios de comunidad los contextos regionales y globales, ya que, como afirmó Steward, "en las sociedades complejas, algunos componentes de la superestructura social, más que la ecología, aparecen como determinantes" (Wolf, 1977, p. 24). También en México Stavenhagen (1979) señalaba la importancia del contexto social nacional para definir a la comunidad indígena. En particular, postuló una Antropología que tomara las perspectivas conceptuales de "clase" y "etnia" superando el legado metodológico de la comunidad, por entenderlo como reduccionista al atender excesivamente cuestiones culturales internas (Stavenhagen, 1979). Desde una perspectiva procesual e historicista, tanto Sariego (2002) cuando toma a la comunidad indígena "como realidad histórica" (p. 77), como Besserer (1999) que ubica la constitución propia de la comunidad indígena mixteca en factores políticos externos e históricos, concretan análisis de contextos como fundamentales factores comprensivos de la "comunidad".

En todo caso, tampoco se puede hablar de una ruptura epistemológica. En el mejor de los casos, se reformularon conceptos para adecuarlos a nuevas realidades y voluntades. Así, la tipología dicotómica desarrollada en el primer apartado se trasladó para conceptualizar la gradación de la totalidad al continuum corporativo cerrado y abierto posible en toda comunidad campesina. Tampoco se abandonó la cuestión cultural, aunque sí quedó francamente subsumida en la perspectiva economicista. No obstante, se erradicó el dogma de la autarquía y aislamiento socio- geográfico, persistiendo, en cambio, la localidad como atributo condicionante.

La nueva comunidad así elucidada como campesina es considerada parte de las sociedades complejas o modernas. Estas influyen sobre la comunidad rural modelándola, y esta se articula a la sociedad-continente, precisamente, mediante la comunidad. Atendiendo el aspecto cultural, este se define ahora como una subcultura; en particular, en lo que se refiere a las comunidades corporativas abiertas, donde cohabitan diversas subculturas, aunque la campesina es hegemónica o mayoritaria y permite "la interacción con el mundo externo" (Wolf, 1977, p. 42-43). En tanto subcultura: 
La característica distintiva de la comunidad campesina corporativa es que conforma un sistema social circunscripto, con límites claros y bien establecidos en relación con sus integrantes y los individuos ajenos a ella. Tiene identidad estructural a lo largo del tiempo. Vista desde afuera, la comunidad como un todo practica una serie de actividades y mantiene determinadas "representaciones colectivas". Vista desde adentro, define los derechos y obligaciones de sus miembros y prescribe gran parte de sus comportamientos. (Wolf, 1977, pp. 28-29)

Aún con deficiencias heredadas, ya que la comunidad como una reificación del método persiste (Rendón, Martínez, Appendini y Salles, 1983; Kearney, 1996) y con inconsistencias parciales concentradas alrededor de la noción asumida de cultura y subcultura demasiado plegadas al sector económico productivo (pareciera que la calidad identitaria la otorgara el sector laboral y, en tal caso, debería abordarse entonces una cultura ocupacional o laboral), los progresos de esta última dicotomía para aprehender el polifacético concepto son notorios. De modo más explícito y detallado:

En efecto, al igual que los que reducen lo campesino a algo anacrónico, quienes visualizan a la unidad campesina como el reducto de lo específico, de lo no capitalista, la constituyen por este mismo hecho en un objeto autocontenido cuya relación con su medio ambiente se convierte necesariamente en un vínculo externo; se define al objeto y se le encierra en una caracterización formal antes de analizar y cuestionar el sentido de sus atributos concretos, dejando fuera de lugar toda pregunta acerca de su historicidad. Ambos enfoques impiden conceptualizar las relaciones que las unidades domésticas establecen entre sí y con el capital y, al considerar al campesinado como una sumatoria de individuos o aglomerados sociales de peculiar estructura suspendida en el tiempo, se muestran incapaces de plantear teóricamente el proceso de su transformación. (Rendón et al., 1983, p. 16)

Además, la revisión materialista deshizo el hechizo tautológico que amenazaba con secuestrar al conocimiento antropológico. De este modo, otras nuevas aportaciones críticas y tipologías fueron introduciéndose en el perfeccionamiento metodológico de la cuestión. Me refiero de nuevo al aporte de Aguirre (1991) que basándose en las categorías enunciadas por Weber (1964) de "comunidad compacta y comunidad de culto" (p. 322), propuso "la comunidad compacta y la centro-ceremonial como tipos mesoamericanos de comunidad" (Aguirre, 1991, p. 26); más tarde, Sariego (2002) retomó la idea ampliando la tipología con su "comunidad 
dispersa de la Tarahumara" (p. 104; p. 128). En algunos casos, estas nuevas propuestas analíticas conformaron nuevos híbridos conceptuales, como fue la "comunidad transnacional" (Besserer, 2004) mientras que en otros, modificaron y enriquecieron la base epistemológica propia.

Entre estas aportaciones, tres son relevantes para el presente estudio de la teoría socio-antropológica. Primeramente, la concepción política de la comunidad; por otra parte, también desde el ámbito politológico, la calidad esencialmente imaginada de toda comunidad; por último, las unidades analíticas constitutivas de la comunidad originadas principalmente desde la etnografía de comunidades indígenas orientada por el estudio de su organización social interna.

La concepción ya sugerida en la relación gemeinschaft-gesellschaft, y suprimida por la obsesión positivista en el equilibrio y la armonía orgánica de las relaciones de dominación establecidas entre ambas formas sociales, tiene su temprano desarrollo para la Antropología mexicana por Aguirre. Este al exponer sus tesis sobre las relaciones dominicales (Aguirre, 1991) entre las comunidades indígenas mesoamericanas y sus correspondientes sociedades continentes mestizas, halla suficientes elementos para afirmar como determinante la dominación política ejercida desde fuera sobre las comunidades indígenas, coincidentes con los cuerpos municipales administrativos de cada nación-Estado implicada. Asimismo, matiza el concepto de homogeneidad interna ya que, aun siendo relativamente cierto, existe una jerarquía de valores personificada rotativamente por individuos o grupos familiares: el sistema de cargos político-religiosos.

Por otra parte, Castro (2005) ahonda en esta misma cuestión política interna. Para este autor, preocupado por los aspectos políticos de las comunidades trasnacionales indígenas oaxaqueñas, urge una revisión permanente en torno a esta diferenciación jerárquica, y los conflictos generados por otros grupos de interés internos, como son las mujeres indígenas (Castro, 2005). La supuesta homogeneidad comunitaria es, una vez más, una representación prescriptiva de "cómo deberían ser las cosas" y no una definición descriptiva de "cómo están siendo las cosas" tal y como se interpreta de sus consideraciones teóricas. Estas emanan de las recomendaciones vertidas por Kearney (1996) para desmontar la reificación del concepto de comunidad: pasar de la diferenciación externa de tipologías de comunidad, a la diferenciación interna de tipologías. De nuevo se está señalando hacia el carácter intrínsecamente complejo de lo social. Castro (2005) apuesta por el conflicto político interno, por ejemplo entre hombres y mujeres, como complejo ideológico-discursivo constituyente de la Comunidad, sin orillar otras reflexiones extraídas de la revisión de los tópicos de la teoría trasnacional: territorio móvil y homogeneidad cultural. 
Precisamente, la transnacionalidad ha derivado teóricamente hacia la afirmación por confirmación empírica de lo que tiene de imaginado la "comunidad trasnacional". El quid de esta condición radica en el carácter inmaterial de una buena parte de los flujos integrantes de los circuitos transnacionales. Estos "paisajes étnicos", como los definió Appadurai (1996) transportan ideas, valores, imágenes y cultura intangible. Es así como la teoría trasnacional afirma que se puede ser migrante trasnacional sin haber abandonado el terruño de origen. La participación en la comunidad de procedencia es posible a pesar de la separación física por la persistencia de las telecomunicaciones, de los derechos y obligaciones, y de los artefactos culturales compartidos y reinterpretados, que recrean un imaginario de copertenencia entre los que se van y los que se quedan, cuyas localidades de residencia simultáneas son compartidas como una experiencia vivida en común.

Regresando a la propuesta tipológica de Tönnies, este también consideraba la existencia social de una "comunidad psicológica", mucho menos constrictiva que otros tipos, pero igualmente perdurable en el tiempo en tanto "habita las conciencias y no las localidades" y está constituida por elementos religiosos, esto establece, para Tönnies, la forma suprema de gemeinschaft. En tanto forma ideal de comunidad, parece sugerir una forma prescriptiva para la unidad de pensamiento, aunque obviamente cada uno de los individuos vive esa experiencia espiritual o ideal de un modo particular, próximo a la descripción empírica de la misma.

En contraste, la "comunidad imaginada" postulada desde la politología del nacionalismo moderno (Anderson, 1993) evidencia sus débitos respecto a la tradición sociológica y antropológica. Muy en especial, con este tipo tonniesiano de la "comunidad psicológica", en tanto la nación es definida como "una comunidad política imaginada como inherentemente limitada" (Anderson, 1993, p. 23) y su carácter imaginado es caracterizado en estos términos:

Porque aun los miembros de la nación más pequeña no conocerán jamás a la mayoría de sus compatriotas (...) pero en la mente de cada uno vive la imagen de su comunión (...) De hecho, todas las comunidades mayores que las aldeas primordiales de contacto directo (y quizá incluso estas) son imaginadas. (Anderson, 1993, p. 23)

En la construcción del término, Anderson apunta a tres elementos irreductibles, a saber: los límites o fronteras (finitas y elásticas), la soberanía (el poder inherente del grupo imaginado y representado por un Estado) y, curiosamente, la amistad o compañerismo, entendido como 
un "compañerismo profundo y horizontal". No menos significativo es su posterior desarrollo para relacionar las raíces del nacionalismo (y por extensión, de las comunidades imaginadas) con las formas religiosas ligadas a la interpretación de la muerte. Las coincidencias con el tipo tonniesiano son concluyentes. Así, podemos equiparar la "comunidad imaginada" con la "comunidad psicológica", y ambas ofrecen puntos de contacto con la condición trasnacional. El sentimiento que liga a los miembros de estas comunidades no sería tanto el afecto producido en la contigüidad espacio-temporal de las prácticas, sino en el anhelo existencial humano a permanecer más allá de la muerte física. Su reproducción como grupo social estaría operada por la circulación de imágenes y rituales, si no puramente religiosos, sí sacros o trascendentales.

Cerrando este apartado dedicado al concepto-método y su desarrollo progresivo, las próximas líneas atenderán a los enfoques que han primado la disección y categorización de las unidades analíticas constitutivas de las comunidades humanas, fragmentando la homogeneidad y la totalidad metodológica. Así, el "sistema de cargos", la "unidad social intermedia" entendida como familia, familia extensa y localidad, los "grupos de culto", los "linajes", las "cofradías", la "unidad doméstica campesina de producción" (Rendón et al., 1983) o simplemente la "unidad campesina de producción" (Stavenhagen, 1979), y el clásico "sistema de parentesco"7 (Millán y Valle, 2003르 y 2003b) no solo atienden su objetivo analítico explícito (la determinación de los elementos constitutivos de los límites comunitarios) sino que también posibilitan operaciones metodológicas que den cuenta de la complejidad constitutiva de las formaciones señaladas primigeniamente como "totales", "aisladas" y "homogéneas". Bien sea atendiendo las redes socio-económicas "al considerarla inserta en el conjunto complejo con sus homólogas y con el capital" (Rendón et al., 1983, p. 27), bien sea considerando las instituciones sociales motoras de esa totalidad metodológicamente constituida.

\section{Cálida vs. realmente existente}

Como se deduce de lo dicho anteriormente, la sola palabra "comunidad" carga una marcación positiva producto de este proceso

\footnotetext{
${ }^{7}$ Para esta recensión de conceptos clásicos de la Antropología me he servido de las etnografías contenidas en los dos tomos de La comunidad sin límites, en particular he atendido la introducción redactada por Saúl Millán al primero de los volúmenes. Aunque se trata de perspectivas conceptuales y metodológicas ciertamente conservadoras y ortodoxas, la aplicación empírica de estas ha concebido modificaciones ad hoc que deben ser consideradas como progresos hábiles en la reconceptualización de la «comunidad» metodológica.
} 
-y otros adyacentes- en su conformación de sentido social. Más que un significado unívoco, este término evoca, tiene poder de evocación. De la nostalgia a la utopía, la voz realiza un recorrido a través de las conciencias individuales y colectivas propagada por la imaginación. Una imaginación alimentada - como sostiene Bauman- por el desencanto y la evasión de una realidad demasiado inhumana, llámese sociedad, modernidad o capitalismo.

Esta comunidad "cálida" solo despierta buenas sensaciones (Bauman, 2006, p. 7). No es pues, un concepto estrictamente científico. Por el contrario, posee una historia derivada de la nostalgia y de la esperanza. Es por ende, el sentido mítico-político de la "comunidad" que:

(...) representa el tipo de mundo al que, por desgracia, no podemos acceder, pero que deseamos con todas nuestras fuerzas habitar y del que esperamos volver a tomar posesión. (...) lo notable de la comunidad es que es algo que "siempre ha sido". Podríamos añadir: "o siempre existirá en el futuro". El de "comunidad" es hoy otro nombre para referirse al paraíso perdido al que deseamos con todas nuestras fuerzas volver (...). (Bauman, 2006, p. 9)

Esta fuerza utopista convierte a la "comunidad" en un instrumento para reclamar un comunitarismo post-societal de "tono ético y un carácter propiamente humano" (Marinis, Gatti e Irazuzta, 2010, p. 373).

En la contraparte, la comunidad realmente existente, o lo que resiste de ella después de siglos de "sociedad", se transfigura como una fórmula que pocos querrían integrar en sus vidas: restrictiva, irreflexiva y que "exige lealtad incondicional y trata todo lo que no esté a la altura de tal lealtad como un acto de traición imperdonable" (Bauman, 2006, p. 10). A cambio de seguridad de todo tipo regula el grado de libertades de sus miembros $y$, derivada de la presión externa, se exhibe ante incertidumbres progresivas.

Zárate (1998) nos trae la empiria casuística de lo arriba expuesto. El "hacer comunidad" supone uno de los ejes estratégicos de organizaciones étnico-campesinas michoacanas, en tanto el discurso ideológico y moral comunitarista es una fuerza política (Zárate, 1998). Así encontramos tres "casos de comunidad" estudiados pertenecientes a la organización UCEZ. Dos de ellos son caracterizados como "auténticos" y un tercero supone a juicio de la autora una comunidad "recreada" o "comunidad de hecho", término puesto en voz de uno de los dirigentes. Ninguna de las tres está exenta de conflictividad interna y su consenso unificador siempre frágil. En similares términos se expresa un trabajo dedicado a la "comunidad mexicana en Estados Unidos". Las autoridades mexicanas, una vez erigido 
el Instituto de Estado correspondiente (Instituto de Mexicanos en el Exterior) recrean nominalmente el idealismo cálido de la comunidad para así objetivar estos sujetos, cuando realmente y aprovechando esa cortina ideológica de "sentidos casi siempre positivos" sobregobiernan a estas poblaciones sin considerarlas plenamente con derechos cívicos (Irazuzta, 2010, p. 280).

\section{Conclusiones}

La producción de conocimiento social es prolija en torno al concepto señalado en la exposición y desarrollo de este escrito. Aunque es amplia la perspectiva binaria como herramienta conceptual comprensiva y explicativa del cambio social, la revisión sucinta arroja claramente un consenso en torno al rol metodológico de la Comunidad en Antropología y Sociología. Sin embargo, la interiorización acrítica de dicho instrumento para el conocimiento devino en un producto de conocimiento, aún más, derivó en un obstáculo epistemológico. Este último, en tanto producto cosificado, arropó por parte de todas las corrientes teóricas un término que condensó valores, sentimientos, ideología y utopías sociales. Aunque estuvo ausente en la argumentación precedente el uso que Turner (1988) dio a communitas en tanto un modelo y un proceso de cambio social basado en aspiraciones utópicas que supone una prístina concreción del sustrato afectivo-ideológico del muy estimado concepto antropológico, sin perder su carácter metodológico útil. Este colofón estructuralista del concepto metodológico aquí revisado y reflexionado reviste varios sentidos y sus correspondientes lecturas. Por una parte, la communitas o antiestructura de Turner confluye con este aspecto político, utópico, incluso revolucionario, de la comunidad cálida. Esto es así por el carácter homogeneizador, igualitario, de las communitas históricas franciscanas o beatnicks. También por la esencia transformadora de la communitas como una fase dentro del proceso de cambio socio-cultural de sujetos y estructuras, tal como argumenta Turner en su obra. Es decir, el concepto en tanto parte de un rito de paso también apunta al devenir histórico, coincidiendo en esto con la perspectiva primigenia planteada por Tönnies y continuada, entre otros, por Redfield: la ambivalente communitas supone un tiempo dentro del orden sistémico, en contraposición a las evocaciones utópicas y las experiencias de vida de los sujetos actores de estos y otros movimientos sociales. La lógica turneriana, coherente con la perspectiva armónica de la community, tal como se desarrolló en anteriores apartados, apunta políticamente hablando a cierto gatopardismo: algo debe cambiar para que todo siga igual. 
En suma, el concepto protagonista de este escrito se caracteriza por una multivocidad que le resta rigor metodológico a pesar de las sucesivas revisiones en contra de su institucionalización/naturalización. Ya Bauman (2006) alude a este carácter político en tanto normativo al incidir en ese cómo deben ser las cosas que arrastra la interpretación implícita de esta noción y que influye, sin duda, en los resultados de la investigación, por mucho que Delgado insista en la necesidad de atender aquellas manifestaciones sensibles del comunitarismo.

Y estimo que esta recensión teórica debe servir para obligarnos a la reflexión de este carácter dual para pasados y próximos estudios socio-antropológicos; para sacudirnos de la humana tendencia a la autocomplacencia y la conformidad con las estructuras consensuadas de conocimiento que se trasladan a nuestra visión de las alteridades. En justa medida, sugiero considerar igualmente el carácter político, en tanto utópico, de Comunidad, para una imprescindible ciencia antropológica aplicada. Superando la ya denunciada reificación de nuestros sujetos de estudio, seres humanos al fin de cuentas, reflexionar sobre esta condición humana a partir de un término tan humanista puede ser un primer toque de acción.

\section{Referencias}

Aguirre, G. (1991). Regiones de refugio. El desarrollo de la comunidad y el proceso dominical en Mestizoamérica. Ciudad de México, México: FCE-INI-UV-Gobierno Estado Veracruz.

Anderson, B. (1993). Comunidades imaginadas. Reflexiones sobre el origen y la difusión del nacionalismo. Ciudad de México, México: FCE.

Appadurai, A. (1996). Modernity at large. Cultural dimensions of Globalization Minnesota: University of Minnesota.

Arizpe, L. (1986). Campesinado y migración. Ciudad de México, México: SEP.

Arizpe, L. (1972). Parentesco y economía en una sociedad nahua. Ciudad de México, México: INI. Bauman, Z. (2006). Comunidad: en busca de seguridad en un mundo hostil. Madrid, España: Siglo XXI.

Besserer, F. (1999). Estudios transnacionales y ciudadanía transnacional. En G. Mummert. (Ed.), Fronteras Fragmentadas (pp. 215-238), Morelia, México: COLMICH-CIDEM.

Besserer, F. (2004). Topografías trasnacionales. Ciudad de México: UAM-Plaza \& Janes.

Castro, Y. (2005). Teoría trasnacional. Revisitando la comunidad de los antropólogos. Revista Cultura y Política, (23), 181-194.

Delgado, M. (2005). Espacio público y comunidad. De la verdad comunitaria a la comunicación generalizada. En M. Lisbona. (Coord.), La Comunidad a debate. Reflexiones sobre el concepto de comunidad en el México contemporáneo (pp. 39-60). Zamora, México: COLMICH-UCACH.

Durkheim, E. (1982). La división del trabajo social. Madrid, España: Akal.

Engels, F. (2003). Revolución y contrarrevolución en Alemania. Valencia, España: No Books.

Irazuzta, I. (2010) Comunidades y gobiernos: la nación y el dominio de los afectos. En Marinis, P., Gatti, G. e Irazuzta, I. (Eds.) La comunidad como pretexto. En torno al resurgimiento al (re) surgimiento de las solidaridad es comunitarias (pp.253-280). Barcelona, España: Anthropos. 
Kearney, M. (1996). Reconceptualizing the Peasantry. Anthropology in global perspective. Oxford: Westview.

Marinis, P. (2010) Sociología clásica y comunidad. En Marinis, P., Gatti, G. e Irazuzta, I. (Eds.), La comunidad como pretexto. En torno al (re)surgimiento de las solidaridades comunitarias. (pp. 347-382) Barcelona, España: Anthropos.

Marx, K. (1974). La dominación británica en India. En Instituto de Marxismo-Leninismo (Ed), Obras escogidas de C. Marx y F. Engels Vol. I (pp. 499-505). Moscú, Rusia: Progreso.

Medina, A. y Quezada, N. (1975). Panorama de las artesanías otomís en el Valle del Mezquital. Ciudad de México, México: UNAM.

Millán, S. y Valle, J. (2003a). La comunidad sin límite (I). Ciudad de México, México: INAH.

Millán, S. y Valle, J. (2003b). La comunidad sin límite. Estructura social y organización comunitaria en las regiones indígenas de México (II). Ciudad de México, México: INAH.

Palerm, A. (1968). Productividad agrícola. Un estudio sobre México. Ciudad de México, México: Editorial Productividad.

Redfield, R. (1960). Anthropology and the primitive community. En R. Redfield. (Ed.), Peasant society and culture (pp. 1-34). Chicago: University of Chicago Press.

Redfield, R. (1973). The little community, and Peasant society and Culture. Chicago: University of Chicago Press.

Rendón, T., Martínez, M., Appendini, K. y Salles, V. (1983). El campesinado en México. Dos perspectivas de análisis. Ciudad de México, México: El Colegio de México.

Roca, J. (2011). Los estudios de comunidad. En J.J. Pujadas i Muñoz et al. (Coords.), Etnografía (pp. 212-223). Barcelona, España: UOC.

Sariego, J. L. (2002). El Indigenismo en la Tarahumara: Identidad, Comunidad, Relaciones Interétnicas y Desarrollo en la Sierra de Chihuahua. Guadalajara, México: INI.

Stavenhagen, R. (1979). Problemas étnicos y campesinos. Ciudad de México, México: INI

Turner, V. (1988). El proceso ritual. Estructura y Antiestructura. Madrid, España: Taurus.

Tönnies, F. (2002). Community and society. London: Courier Dover.

Tönnies, F. (1963). Community and society. New York: Harper Torchbooks.

Wolf, E. R. (1977). Tipos de campesinado latinoamericano: una discusión preliminar. En E. R. Wolf. (Ed), Una tipología del campesinado latinoamericana. Buenos Aires, Argentina: Nueva Visión.

Zárate, M. (1998). En busca de la comunidad: identidades recreadas y organización campesina en Michoacán. Zamora, México: Colegio de Michoacán. 